Mark Jansen D. G. Austria, MD

Rodante A. Roldan, MD

Department of Otolaryngology

Head and Neck Surgery

Rizal Medical Center

\title{
Laryngeal Cancer Neck Node Metastases: Patterns of Spread
}

\begin{abstract}
Objective: To determine the patterns of neck node metastases of patients with laryngeal carcinoma in our institution.
\end{abstract}

\section{Methods:}

\section{Design: Chart Review \\ Setting: Tertiary Public Hospital}

Participants: Records of thirty-eight (38) laryngeal cancer patients who underwent laryngectomy with neck dissection from January 2010 to January 2017 were considered.

Results: Records of 34 laryngeal cancer patients with ages ranging from 45-72 years old were included. The most common subsite was the glottis with 19 (55.88\%) patients. The distribution of neck node metastases for all subsites were 0/64 (0\%) for level I, 22/64 (34.37\%) for level II, $12 / 64(18.75 \%)$ for level III, $7 / 64$ (10.93\%) for level IV, 0/64 (0\%) for level V, and 1/64 (1.56\%) for level VI. Distributions of lymph nodes per subsite for supraglottic SCCA were $0(0 \%)$ for level I, 3/22 (13.63\%) for level II, 2/12 (16.66\%) for level III, 1/7 (14.28\%) for level IV, 0 (0\%) for level V, and $0 / 1(0 \%)$ for level VI. For glottic SCCA, they were 0 (0\%) for level I, 12/22 (54.54\%) for level II, 8/12 $(66.66 \%)$ for level III, 3/7 (42.85\%) for level IV, $0(0 \%)$ for level V, and 1/1 (100\%) for level VI; and for transglottic SCCA, they were 0 (0\%) for level I, 7/22 (31.81\%) for level II, 5/12 (41.66\%) for level III, $3 / 7(42.85 \%)$ for level IV, 0 (0\%) for level V, and 0/1 (0\%) for level VI.

Conclusion: Our findings show that neck node levels II, III and IV are most frequently affected in laryngeal carcinoma patients in our sample and may guide recommendations for neck dissection in our institution.

Keywords: Laryngeal Cancer, Metastases, Neck dissection, Supraglottic, Subglottic, Glottic, Transglottic

Lymph nodes may serve as barriers to the spread of tumor cells, as vehicles for progression of tumor spread within lymphatics, and as vehicles for progression of tumor spread from lymphatics to more remote sites. ${ }^{1}$ There are predictable pathways of lymphatic drainage within the subsites of the upper aerodigestive tract. ${ }^{2}$ Neck dissection is a surgical procedure in head and neck cancers to either remove or prevent disease progression.

The role of elective treatment of the neck in laryngeal cancer continues to be controversial and variations in type and extent of surgical dissection have evolved. ${ }^{3} \mathrm{~A}$ complete functional neck 
ORIGINAL ARTICLES

dissection has been considered unnecessarily extensive for treatment of the clinically negative neck and therefore selective neck dissection is now routinely employed for elective and some therapeutic neck dissections in patients with laryngeal cancer. ${ }^{4}$

To guide our recommendations for neck dissection, the objective of this paper was to determine the pattern of neck node metastases of patients with laryngeal carcinoma in our institution.

\section{METHODS}

With Ethical Review Board (ERB) approval, a chart review of all patients with laryngeal carcinoma who underwent laryngectomy and neck dissection in the Department of Otolaryngology-Head and Neck Surgery of Rizal Medical Center from January 2010 to January 2017 was performed. The neck dissections done were either prophylactic or elective and the type of dissection was selective or modified radical. Data was retrieved from the hospital records section and recorded using Microsoft Excel 2010 version 14.0.4760.1000 (32-Bit) (Microsoft Corp., Redwood, CA, USA). Only the initials of patients were recorded to maintain confidentiality. Records of 38 patients were initially considered but because of inadequate data and chart unavailability, 4 records were excluded. Data obtained were gender, age, TNM staging, type and number of neck dissections performed and relative frequency of positive nodes in each nodal group for each subsite. Descriptive statistics were generated using the same MS Excel program.

\section{RESULTS}

The records of 34 patients who underwent total laryngectomy with neck dissection were included in our study (31 males, 3 females) with ages ranging from 45 to 72 years old. Table 1 shows the TNM staging of our patients with most cases in Stage 4 (58.82\%). There were sixtyfour (64) neck dissections performed, sixty (60) selective and four (4) modified radical, thirty-two (32) on the right and thirty-two (32) on the left neck, respectively. The subsites involved were supraglottic in 5 (14.7\%), glottic in 19 (55.88\%) and transglottic in 10 (29.41\%). The relative frequency of positive nodes in each nodal group for each subsite is shown in Table 2.

Table 1. TNM Staging

\begin{tabular}{|c|c|c|}
\hline TNM Stage & Number of Patients (N) & Percentage (\%) \\
\hline I & 2 & 5.88 \\
\hline II & 1 & 2.94 \\
\hline III & 11 & 32.35 \\
\hline IVa & 20 & 58.82 \\
\hline TOTAL & 34 & 100.00 \\
\hline
\end{tabular}

Table 2. Relative frequency of positive nodes in each nodal group for each subsite

\begin{tabular}{|c|r|r|r|}
\hline $\begin{array}{c}\text { Lymph Node } \\
\text { Levels }\end{array}$ & $\begin{array}{c}\text { Supraglottic } \\
\text { (n/N) \% }\end{array}$ & \multicolumn{1}{|c|}{$\begin{array}{c}\text { Glottic } \\
\text { (n/N) \% }\end{array}$} & \multicolumn{1}{c|}{$\begin{array}{c}\text { Transglottic } \\
\text { (n/N) \% }\end{array}$} \\
\hline I & 0 & 0 & 0 \\
\hline II & $(3 / 22) 13.63$ & $(12 / 22) 54.54$ & $(7 / 22) 31.81$ \\
\hline III & $(2 / 12) 16.66$ & $(8 / 12) 66.66$ & $(5 / 12) 41.66$ \\
\hline IV & $(1 / 7) 14.28$ & $(3 / 7) 42.85$ & $(3 / 7) 42.85$ \\
\hline $\mathrm{V}$ & 0 & 0 & 0 \\
\hline $\mathrm{VI}$ & 0 & $(1 / 1) 100$ & 0 \\
\hline
\end{tabular}

\section{DISCUSSION}

Among the 34 laryngeal cancer patients who underwent total laryngectomy with neck dissection in our study, the most commonly involved lymph node groups were levels II, III and IV. The lymph node groups involved per laryngeal subsite in our sample were levels II, III, IV for supraglottic; levels II, III, IV,VI for glottic; and levels II,III,IV for transglottic cancer.

Supraglottic SCCA usually metastasizes to levels II, III and IV because of its rich lymphatic network and midline location that has a high propensity for bilateral lymph node involvement. ${ }^{5}$ The lymphatic channels from the supraglottis pass through the thyrohyoid membrane anddrainintothejugularchain. ${ }^{5,6}$ Theposteriorcervicalnodes(levelV)are seldom involved, and submandibular (level IB) and submental (level IA) nodes are almost never involved. ${ }^{5}$ The results of our study are comparable to those of Lindberg et al. where the main spread was along levels II, III and IV among 2,044 patients including supraglottic SCCA. Our findings also echo those of Candela et al. ${ }^{7}$ that revealed levels II, III and IV had the highest risk of nodal metastases from squamous cell carcinoma among 247 patients who underwent 267 neck dissections. ${ }^{7,8}$

On the other hand, the nodes at risk of metastasis from glottic SCCA are those in levels II, III, IV and VI. ${ }^{6}$ Bilateral or contralateral metastases are rare because the true vocal folds are nearly devoid of lymphatics. ${ }^{5,6}$ It is interesting to note that patients with glottic SCCA who were operated on in our institution had multiple lymph node involvement (II, III, IV) at the time of surgery. This may be explained by the fact that majority (52.63\%) of glottic SCCA in our institution presented at Stage 4a. On the other hand, our series had only one patient with level VI involvement. This is in contrast to the study of Waldfahrer et al. ${ }^{9}$ that reported an incidence of occult metastases of $18 \%$. Though the reasons for this need to be investigated, one possible explanation may involve the diligence of the surgeon and pathologist in identifying and isolating level VI lymph nodes in the specimen, separating them from the primary tumor. 


\section{ORIGINAL ARTICLES}

Primary subglottic carcinoma is rare, constituting from $1-3.6 \%$ of the laryngeal cancers reported in the literature. ${ }^{10}$ Paratracheal node (level VI) metastases are more frequent in patients with primary subglottic carcinoma. ${ }^{11}$ The rarity of primary subglottic carcinoma and late stage of presentation in our patients may have limited us from obtaining such cases.

Our study is limited to one type of carcinoma and by a small sample size. Hence, we recommend future multi-center studies that include the experience of other institutions. Moreover, though not a formal part of the study, we noticed that majority of our patients presented with cancer in later stages. While searching for and addressing underlying reasons for this, we should strengthen our head and neck cancer awareness and education programs for health promotion, disease prevention, and early detection. Meanwhile, our findings that neck node levels II, III and IV are most frequently affected in laryngeal carcinoma patients in our sample may guide recommendations for neck dissection in our institution.

\section{REFERENCES}

1. Aarsvold JN, Alazraki NP. Update on detection of sentinel lymph nodes in patients with breast cancer. Semin Nucl Med. 2005 Apr; 35(2):116-28. Epub 2005/03/15. DOI: 10.1053/j. semnuclmed.2004.11.003; PMID: 15765374.

2. Mukherji SK, Armao D, Joshi VM. Cervical nodal metastases in squamous cell carcinoma of the head and neck: what to expect. Head Neck. 2001 Nov; 23(11): 995-1005. Epub 2002/01/05. PMID: 11754505.

3. Ferlito A, Rinaldo A, Silver CE, Robbins KT, Medina JE, Rodrigo JP, et al. Neck dissection for laryngeal cancer. J Am Coll Surg. 2008 Oct; 207(4):587-93. Epub 2008/10/18. DOI: 10.1016/j. jamcollsurg.2008.06.337; PMID: 18926464.

4. Genden EM, Ferlito A, Silver CE, Jacobson AS, Werner JA, Suarez C, et al. Evolution of the management of laryngeal cancer. Oral Oncol. 2007 May; 43(5):431-9. Epub 2006/11/23. DOI: 10.1016/j.oraloncology.2006.08.007; PMID: 17112771.

5. Cahlon O, Lee N, Le QT, Kaplan MJ, Colevas AD. Cancer of the Larynx. In: Hoppe R, Phillips TL, Roach III M (editors). Leibel and Phillips Textbook of Radiation Oncology 3rd ed. Vol 2. Philadelphia, PA; Saunders. 2010; 31, 642-665.

6. Armstrong WB, Vokes DE, Verma SP. Malignant Tumor of the Larynx. In: Flint PW, Haughey BH, Lund VJ, Niparko JK, Robbins KT, Thomas JR, et al (editors). Cummings Otolaryngology Head and Neck Surgery, 6th ed. Vol 2. Philadelphia (PA): Mosby, c2010. P1613-1614.

7. Candela FC, Shah J, Jaques DP, Shah JP. Patterns of cervical node metastases from squamous carcinoma of the larynx. Arch Otolaryngol Head Neck Surg. 1990 Apr; 116(4): 432-5. Epub 1990/04/01. PMID: 2317325.

8. Byers RM, Wolf PF, Ballantyne AJ. Rationale for elective modified neck dissection. Head Neck Surg. 1988 Jan-Feb; 10(3): 160-7. Epub 1988/01/01. PMID: 3235344.

9. Waldfahrer $\mathrm{F}$, Hauptmann B, Iro H. [Lymph node metastasis of glottic laryngeal carcinoma] Laryngorhinootologie. 2005 Feb; 84(2): 96-100. Epub 2005/02/16. DOI: 10.1055/s-2004-826075 PMID: 15712044.

10. Santoro R, Turelli M, Polli G. Primary carcinoma of the subglottic larynx. Eur Arch Otorhinolaryngol. 2000 Dec; 257(10): 548-51. Epub 2001/02/24. PMID: 11195034.

11. Coskun HH, Medina JE, Robbins KT, Silver CE, Strojan P, Teymoortash A, et al. Current philosophy in the surgical management of neck metastases for head and neck squamous cell carcinoma. Head Neck. 2015 Jun; 37(6):915-26. Epub 2014/03/14. DOI: 10.1002/hed.23689; PMID: 24623715 PMCID: PMC4991629. 